\title{
Corrupção na saúde no Brasil: reflexão à luz da abordagem baseada nos Direitos Humanos
}

\author{
Corruption in health in Brazil: reflections in the light of the Human Rights- \\ based approach
}

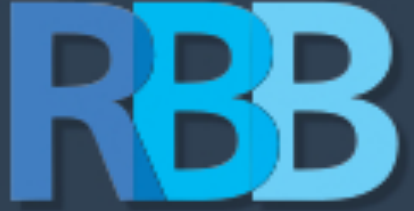

Revista Brasileira de Bioética

Aline Albuquerque

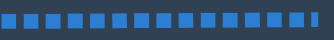

Cátedra Unesco / Programa de Pós-Graduação em Bioética da UnB, Brasília, DF, Brasil alineaoliveira@hotmail.com

Camila Nascimento de Souza

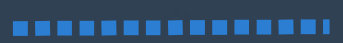
Centro Universitário de Brasília (UniCeub), Brasília, DF, Brasil camilanascimento.s@hotmail.com
Resumo: Este artigo tem como escopo analisar a incorporação da abordagem baseada em direitos humanos para o enfrentamento da corrupção no âmbito do SUS. Trata-se de pesquisa teórica realizada com base em artigos específicos sobre corrupção na saúde, bem como outros de natureza documental. Quanto a abordagem baseada nos direitos humanos, a pesquisa fundamentou-se em documentos produzidos pela ONU sobre Direitos Humanos e corrupção. Concluiu-se que, no Brasil, os mecanismos de transparência e accountability no âmbito do SUS devem ser aprimorados, consolidados e fortalecidos de modo a se enfrentar veementemente a corrupção. Observou-se também que a constatação da sociedade brasileira de que recursos da saúde são apropriados por agentes privados contribui para minar os movimentos em prol do necessário incremento dos recursos públicos para o financiamento da saúde. Por fim, destaca-se que o aumento do volume de valores para a saúde deve ser acompanhado do real comprometimento com o combate à corrupção.

Palavras-chave: corrupção, sistema de saúde, direitos humanos, Brasil.

Abstract: This article aims to analyze the incorporation of the human rights approach to addressing corruption within the brazilian public health system (SUS). Is a theoretical research based on specific articles on corruption in health, as well as others of a documentary nature. Concerning the human rights approach, the study was based on UNITED NATIONS (UN) documents on human rights and corruption. Was concluded that, in Brazil, transparency and accountability mechanisms within the scope of SUS should be improved, consolidated and strengthened in order to face corruption. It is also concluded that the Brazilian society's observation that health resources are appropriated by private agents contribute to undermine movements in favor of the necessary increase of public resources for health financing. Finally, should be noted that the increase in the volume of health values must be accompanied by a real commitment to combat corruption.

Keywords: corruption, health system, human rights, Brazil. 
A corrupção na saúde é uma realidade global. Presente em todos os sistemas de saúde do mundo, é especialmente mais grave se comparada com outras formas, pois limita o desenvolvimento humano e econômico, bem como coloca os pacientes em situação de risco (Mackey, 2016). A corrupção na saúde impacta negativamente na provisão de serviços de saúde e prejudica, particularmente, os mais pobres (Vian, 2008).

Combatê-la envolve primordialmente entender como ocorre e em que circunstâncias e quais são seus agentes, logo, consiste numa análise de ambientes, agentes e maneiras de agir. A partir dessa análise, é possível traçar estratégias para o enfrentamento adequado e específico do problema.

A corrupção na saúde traz em si um paradoxo: concomitantemente revela-se uma questão cujas repercussões são evidentes, como a escassez de recursos sanitários, e, por outro lado, também mostra-se velada em razão de alguns fatores que serão apontados neste artigo. Sendo assim, a corrupção na saúde é vivenciada por todos na medida em que suas consequências são objetivamente experimentadas por aqueles que são destinatários dos sistemas de saúde, que observam os investimentos na saúde não gerarem resultados positivos para a população (Savedoff, 2016). Registre-se o estudo realizado em 2013, por Biderman e Avelino, no qual foi apurado, a partir da análise de dados de relatórios da auditoria da Controladoria Geral da União, que a corrupção impacta negativamente os padrões de saúde relacionados com a mortalidade em hospitais e estabelecimentos de saúde nos Municípios brasileiros. Assim, consoante o estudo, existe uma nítida relação entre os índices de corrupção e de mortalidade nos Municípios brasileiros (Biderman e Avelino, 2013). Desse modo, sustenta-se neste artigo que o problema da corrupção na saúde acarreta consequências maléficas para toda a população, notadamente para a parcela de menor renda, porquanto $71 \%$ dos brasileiros têm os serviços de cuidados em saúde do Sistema Único de Saúde como referência de atendimento (Ministério da saúde, 2015).

Por outro lado, a corrupção na saúde também se mostra um tema oculto, pois comumente os sistemas de saúde não contam com instrumentos de accountability e de transparência. Sendo assim, é tortuoso analisar de forma adequada e sistemática o tema em razão da falta de informação sobre contratos e gastos em saúde, ou seja, há falta de transparência dos atos de gestão praticados na esfera da saúde. Acrescenta-se ainda o fato de que, usualmente, a prática da corrupção nos sistemas de saúde é de certa forma tão enraizada e institucionalizada que muitos nem ousam questioná-la ou não percebem seu caráter ilícito ou imoral. Ressalte-se que a construção da moralidade de determinado espaço social é fator crucial na escolha de 
cada indivíduo em praticar ou não um ato corrupto. De fato, a influência social age profundamente na maneira que o indivíduo se comporta em todos os âmbitos de sua vida, inclusive na esfera pública. No caso do Brasil, as tentativas de aproveitamento de situações ou circunstâncias para ganho privado na esfera da saúde são noticiadas cotidianamente, portanto, se nota, empiricamente, que há uma ambiência propícia para o cometimento de atos de corrupção.

Com o objetivo de aprofundar os estudos sobre a corrupção na saúde, este artigo tem como escopo analisar incorporação da abordagem baseada em direitos humanos para o enfrentamento da corrupção no âmbito do Sistema Único de Saúde - SUS de modo a contribuir para a discussão do "padrão de uso do orçamento público" como proposto por Wagner, pois a discussão sobre o aumento dos recursos para a saúde no Brasil perpassa o tema da corrupção (Wagner, 2017).

Destaca-se que quanto ao recorte deste artigo, não se objetiva realizar ampla investigação sobre a corrupção no âmbito do SUS, mas analisar alguns fatores que a propiciam. Registre-se, ademais, que se trata de pesquisa teórica, realizada com base em artigos específicos sobre corrupção na saúde, bem como de natureza documental, porquanto a abordagem baseada nos direitos humanos fundamentouse nos documentos produzidos pela Organização das Nações Unidas - ONU sobre direitos humanos e corrupção. Para tanto, inicia-se pela demarcação do que seja corrupção e das características dos sistemas de saúde que desafiam o enfrentamento da corrupção na saúde. Em seguida, serão identificadas as modalidades de corrupção na saúde, para então passar-se a análise dos fatores que propiciam os atos corruptos, enquanto lacunas ou graves deficiências dos sistemas que propiciam a sua ocorrência. Por fim, com base no referencial dos direitos humanos aplicado à corrupção, desenvolvidos nos documentos produzidos pela ONU.

\section{Fatores que propiciam a corrupção nos sistemas de saúde}

Os sistemas de saúde são propensos à corrupção por diversos fatores (Savedoff, 2016). A complexidade certamente contribui para essa suscetibilidade. Contudo, inicialmente, tem-se como objetivo demarcar conceitualmente o significado de corrupção. Sob a ótica ética e social, um ato de corrupção não necessariamente corresponde a uma norma legal. Como exemplo de situações em que a moralidade da conduta é passível de questionamento, mas não há ilicitude, somente em 2011, 140 audiências foram pedidas por deputados e senadores com o diretor-presidente e 
a cúpula da ANVISA para discutir questões sobre empresas farmacêuticas, de alimentos e laboratórios (Estadão, 2012).

O diretor-chefe da ANVISA afirmou que mais da metade das 140 audiências ocorreu para atender o interesse de alguma indústria, que em sua maioria tinha sede no Estado ou na cidade do parlamentar. Outro caso recorrente que exemplifica essa dificuldade em traçar os contornos da moral e do direito, diz respeito ao conflito de interesses entre empresas e médicos. Alguns países regulam o conflito de interesses entre empresas e médicos por meio de leis de transparência com vistas a assegurar que os médicos não coloquem o ganho financeiro a acima do bem-estar do paciente. Nos Estados Unidos, a lei obriga que viagens, jantares, palestras, consultorias e outros sejam declarados e tornados públicos, ou seja, qualquer pessoa pode ter acesso aos laços que o profissional tem com empresas. Esses pontuam que a corrupção, entendida como uso de poder público ou confiado para ganho privado (Vian, 2008), extrapola a tipificação penal adotada na legislação criminal brasileira. Sendo assim, este artigo parte desse conceito ético-social de corrupção para tratar da temática, objeto desta análise. Em seguida, serão abordados três fatores que tornam os sistemas de saúde propícios para a corrupção.

\section{Os sistemas de saúde demandam elevado nível de aporte financeiro}

Os serviços de saúde demandam elevado nível de investimento financeiro, notadamente se tomar em consideração o crescente aporte de tecnologia médica, bem como o envelhecimento da população global que gera o incremento dos gastos em saúde. No Brasil, segundo o Tribunal de Contas da União, a Função Saúde constituiu, em 2014, o terceiro maior conjunto de despesas no orçamento da União, com valores liquidados de R\$ 86 bilhões, dos quais $67 \%$ foram executados de forma descentralizada (por Estados e Municípios) e 30\%, de forma direta (FiscSaúde, 2015). Dessa forma, o volume de verbas investidas na saúde faz com que o ambiente dos sistemas de saúde seja também mais suscetível a desvio, ou seja, os agentes públicos manejam volume maior de recursos financeiros, assim, a oportunidade de controlar valores torna os sistemas mais passíveis de terem seus recursos apropriados ou utilizados para fins privados (Vian, 2008). Tal fato não conduz à conclusão de que o problema seria solucionado por meio do decréscimo do financiamento público dos sistemas de saúde, mas sim o enfrentamento da corrupção se dá pelos meios a seguir tratados neste artigo.

\section{Os sistemas de saúde contam com a multiplicidade de atores}

Outro fator que explica a complexidade dos sistemas de saúde e a sua susceptibilidade à corrupção é a multiplicidade de atores (Mackey, 2016). Embora o 
Estado seja o responsável por regular as relações no âmbito sanitário, os sistemas de saúde, em razão da intrincada rede de prestações e de serviços envolvidos, os de saúde abarcam profissionais de saúde, prestadores públicos e privados, gestores, empresários, cientistas e outros. Assim, múltiplos atores atuam em conjunto para que os pacientes e usuários dos sistemas de saúde sejam providos por meio de bens e serviços (Wagner, 2017). O Estado, em seu papel de provedor direto ou regulador, tem o dever de assegurar que todo esse maquinário funcione de modo que haja a prestação final de saúde aos pacientes e usuários. Para ilustrar, uma pessoa adoece e precisa de atendimento médico, para tanto, se dirige a um hospital particular provedor privado do serviço de saúde - faz uso de seu plano de saúde - o operador do plano é o intermediário entre o paciente, o hospital e o regulador final que é o Estado - e é atendido por um médico, profissional liberal que é parte do sistema como provedor. O médico the prescreve medicamento que é adquirido em uma farmácia, após serem produzidos pela indústria farmacêutica e regulados por meio da ANVISA, que também regula as farmácias. Caso o mesmo paciente tivesse se direcionado a um hospital público, a infraestrutura, os recursos humanos e materiais teriam sido objeto de licitações e contratos celebrados pelo Estado.

Assim, constata-se que os sistemas de saúde abarcam uma série de relações jurídicas e de poder, ou seja, há múltiplas microrelações que são suscetíveis à corrupção. No exemplo dado, podem-se observar relações jurídicas e de poder entre Estado/indústria farmacêutica, indústria farmacêutica/médico, hospital/operadora do plano de saúde, e hospital/Estado, dentre outras. Dessa forma, na medida em que os sistemas de saúde englobam atores diversos com interesses, modus operandi, legislações, e culturas institucionais variados, torna-se árdua a tarefa de lidar com a corrupção em tal seara.

\section{A assimetria de informações entre os operadores dos sistemas de saúde e a população}

É também fator que se associa à complexidade dos sistemas de saúde e sua susceptibilidade à corrupção a assimetria de informações entre os provedores e profissionais do sistema de saúde e a população (Mackey, 2016). A teoria da informação assimétrica, usada principalmente na economia, assenta que a assimetria de informação ocorre quando em uma negociação, por exemplo, uma parte tem mais informação do que a outra e com isso obtem vantagem. No âmbito da saúde, a despeito de não caracterizar negociação entre operadores e pacientes e usuários, mas prestação de serviço de saúde, como regra, a população é composta por pessoas leigas em tal matéria, que não detém as mesmas informações técnicas e científicas que o provedor e o profissional do sistema de saúde.

A saúde envolve conhecimentos científicos e técnicos, por vezes altamente especializados, o que gera uma defasagem entre o conhecimento dos provedores e 
profissionais e a população. Assim, torna-se mais difícil monitorar os gastos, contratos e escolhas da gestão em saúde na medida em que envolvem razões de ordem médica e científica desconhecidas para a maior parte das pessoas. Dessa forma, o distanciamento entre as justificativas técnicas e científicas para a determinada aquisição de medicamentos e insumos de saúde, por exemplo, é de difícil compreensão pela maior parte da população, o que acarreta certo desinteresse pelas tarefas de monitoramento e acompanhamento da gestão, tornando os sistemas de saúde menos fiscalizados pela sociedade civil.

Sendo assim, constata-se que os sistemas de saúde apresentam características peculiares que os tornam mais passíveis de estarem sujeitos à corrupção, considerando suas modalidades variadas, como será apontado no tópico subsequente.

\section{Modalidades de corrupção nos sistemas de saúde}

A corrupção na saúde pode ser materializada por meio de condutas diversificadas. Com base na formulação de Taryn Vian, serão apresentadas sete modalidades de corrupção, considerando que algumas são mais evidentes e de maior ocorrência no Brasil, com referência a essas, serão trazidos exemplos com a finalidade de ilustrá-las. (Vian, 2008).

\section{Pagamentos informais feitos diretamente a profissionais de saúde}

No dia-a-dia dos sistemas de saúde, pagamentos informais, aqueles que não são legalmente previstos, podem ocorrer entre os profissionais de saúde e os pacientes. As motivações são múltiplas, como a exigência por parte do profissional de pagamento para o atendimento, a prescrição de determinado remédio ou exame e a realização de procedimentos. A principal consequência desse tipo de corrupção é a redução do acesso a serviços e bens de saúde por parte da população que não pode arcar com tal pagamento, o que repercute negativamente sobre a equidade em saúde. Com efeito, o pagamento pelo paciente para ser atendido ou submetido a determinado procedimento pode acarretar a exacerbação de desigualdades sociais, isto é, alguns pacientes poderão pagar os valores exigidos, porém, outros não têm condições de arcar com tais quantias, o que fará com que a corrupção provoque a desassistência de pacientes de baixa renda.

Nomeação e permanência em cargos dos sistemas de saúde devido ao repasse de valores a membros do governo

Outro tipo de corrupção na saúde é a nomeação e a permanência em cargos dos sistemas de saúde devido ao repasse de valores a membros do governo. No caso específico do Brasil, além do repasse assinalado, constata-se a ampla nomeação de pessoal para cargos no âmbito do Sistema Único de Saúde em razão do contato ou 
afiliação política. Conforme pontuado por Wagner: "Em Portugal, por exemplo, os cargos de gestão e administração da saúde são feitos por concursos internos, no Brasil, todos os cargos são de confiança. Os prefeitos indicam, e o critério é de competência, e isso fazer parte de um grupo político" (Wagner, 2017). Essa prática de corrupção é extremamente perniciosa para os sistemas de saúde, porquanto passam a ser geridos por amadores e/ou pessoas regidas pelo autointeresse, ou, em algumas situações, há o desvio de recursos públicos a fim de atender à demanda daqueles que indicaram o nomeado para o cargo. Com efeito, a principal consequência dessa modalidade de corrupção é o aumento da quantidade de pessoas desqualificadas tecnicamente para exercer cargos, e, ademais, as pessoas nomeadas podem se sentir pressionadas a abusar do poder para financiar sua nomeação (Vian, 2008,).

Como apontado, os sistemas de saúde são complexos e prescindem de pessoas técnicas e adequadamente preparadas para geri-los, caso contrário, o sistema padecerá pela falta de gestão técnica, profissional e norteada pelos interesses da população.

\section{Absenteísmo ilegal dos profissionais de saúde de cumprimento reduzido do horário de trabalho}

O planejamento e a gestão dos sistemas de saúde perpassam pelo adequado número de profissionais para o atendimento com qualidade dos pacientes, o que se ancora na quantidade do atendimento e na sua duração (Vian, 2008). Caso os profissionais de saúde se abstenham ilegalmente do trabalho ou não cumpram a sua jornada, por obvio, o atendimento dos pacientes torna-se desqualificado. Sendo assim, a principal consequência do absenteísmo profissional sem respaldo legal é a redução do acesso e da provisão de serviços. Essa modalidade de corrupção é constatada no país, como exemplo, em 2013, médica do Serviço de Atendimento Móvel de Urgência - SAMU da cidade de Ferraz, em São Paulo, foi presa com seis dedos de silicone que usava para burlar a biometria do ponto de trabalho (Portal G1, 2013). Outro caso se deu em Brasilia, em março de 2017, quando um esquema de manipulação de folhas de ponto de médicos do Hospital de Base foi descoberto. A ação do Ministério Público do Distrito Federal e Territórios e da Polícia Civil do Distrito Federal investiga profissionais suspeitos de fraudar horas extras para aumentar ganhos, assim, eram lançadas horas não realizadas, bem como foram apurados indícios de falsificação de documentos para justificar abonos concedidos (Correio Braziliense, 2017).

Propinas dirigidas a profissionais e gestores de saúde para cometerem ou permitirem a prática de atos ilegais

Essa modalidade de corrupção na saúde se dá mediante o pagamento de valores a médicos com a finalidade de conseguir a prescrição de medicamentos e/ou atestados de saúde. Para ilustrar, no ano de 2016, durante as eleições municipais da 
região metropolitana de São Paulo, um médico foi flagrado por vídeo prescrevendo atestado em troca de voto a determinado candidato à Prefeitura de Arujá (R7, 2016) . 0 médico ainda prometia para o paciente que, caso o candidato à Prefeitura fosse eleito, o médico seria nomeado Secretário Municipal de Saúde da cidade.

Essa prática corrupta acarreta a quebra de confiança da população nos profissionais de Medicina, o que é extremamente maléfico para o sucesso dos sistemas de saúde, assim como pode gerar prescrições em desconformidade com as evidências científicas, ocasionando danos à saúde do paciente e repercussões na saúde pública.

\section{Corrupção nas licitações de serviços e bens de saúde}

O sistema de saúde demanda, para sua provisão, a aquisição de ampla gama de serviços e bens, como medicamentos, órteses, próteses, equipamentos tecnológicos, dentre outros. Para que a aquisição seja a mais adequada possível, considerando os parâmetros de economicidade e de qualidade, os agentes públicos lançam mão do procedimento licitatório. Porém, quando há corrupção em tal procedimento, observa-se - superfaturamento de serviços e bens, assim como a falta de qualidade dos bens ofertados à população ou dos equipamentos construídos para abrigarem hospitais, postos e clínicas de saúde. No Brasil, chama-se atenção para o rotineiro problema atrelado à corrupção em licitações na esfera da saúde, como apontado por Wagner (2017) : "Pela dificuldade de fazer licitações, sai verba para construir hospital e não se constrói. O povo brasileiro não confia no Estado, com base em evidências" (Wagner, 2017). A corrupção nas licitações gera números prejuízos para os sistemas de saúde, tais como a escassez de medicamentos e insumos em virtude da utilização dos recursos financeiros com outras finalidades; baixa qualidade das instalações de saúde, pois são empregados materiais de qualidade inferior para gerar o superfaturamento; e descrédito da população no próprio sistema, o que impulsiona os discursos privatistas e o desmantelamento dos serviços públicos de saúde.

\section{saúde}

Furto ou mau uso dos bens destinados à prestação de serviços de

Os bens utilizados na prestação de serviços de saúde são escassos e demandam uso adequado e responsável. Quando isso não ocorre, ou seja, são furtados ou mal utilizados, há a constatação da corrupção e a repercussão negativa para o atendimento à saúde da população.

\section{Fraudes diversas}

As principais consequências dessa modalidade de corrupção consistem no desvio de recursos sanitários e, consequentemente, na insuficiência de valores para a prestação efetiva dos serviços de saúde, além da qualidade inferior do serviço 
prestado e do desabastecimento de medicamentos e insumos de saúde. Essas fraudes se concretizam das mais variadas formas, tais como forjar pacientes fantasmas e a venda de lugar em filas de atendimento.

A fim de ilustrar, destaca-se o caso da denúncia formulada pelo Ministério Público Federal de dois médicos e uma empresa por suposta fraude contra o SUS dentro de hospital do Distrito Federal. Em 2012, a família de paciente idosa com fratura no quadril foi orientada a comprar uma prótese importada no valor de R\$ 11 mil, porém os médicos e a empresa que atenderam a paciente idosa cobraram do SUS uma prótese nacional que custou, na época, ao erário o valor de R\$1,700 (Jus Brasil, 2012).

\section{Desvio de recursos destinados a políticas de saúde}

Por fim, a última modalidade de corrupção compreende as práticas que consubstanciam desvios de verbas destinadas a políticas de saúde. Conforme apontado em relação a outras modalidades, a principal consequência é a falta de recursos para as políticas e a qualidade inferior dos serviços prestados, dos insumos adquiridos e a falta da provisão de medicamentos. De modo ilustrativo, registre-se a prisão temporária do prefeito de São Francisco de Itabapoana e de mais quatro pessoas investigadas por participação em esquema de desvio de verbas públicas destinadas à saúde no Município. De acordo com o Inquérito Policial instaurado, a fraude envolvia o superfaturamento de exames laboratoriais que eram pagos diretamente a determinada clínica privada, com a rubrica da Prefeitura de São Francisco de Itabapoana, por meio de convênio com o Ministério da Saúde. "Além disso, a quadrilha manteria a prática de prestar informações falsas ao SUS sobre exames fictícios" (Jus Brasil, 2012).

\section{Fatores que propiciam a corrupção nos sistemas de saúde}

Após a análise da complexidade do sistema de saúde e das modalidades de corrupção, cabe o exame dos fatores que propiciam a corrupção nos sistemas de saúde, o que será enunciado conforme os estudos feitos por Taryn Vian.

A corrupção na saúde aponta para o uso do poder com a finalidade de se obter ganho privado, desse modo, a fim de se alcançar essa finalidade, três elementos devem estar presentes: a) a oportunidade, que envolve o uso indevido de uma vulnerabilidade do sistema; b) a pressão ou o incentivo do uso de algum benefício do sistema de saúde para um motivo individual; c) a racionalização, que consiste nos argumentos construídos pelo agente corrupto para justificar suas práticas corruptas (Vian, 2008). 
A oportunidade envolve as lacunas ou deficiências do sistema que permitem que a corrupção ocorra e podem ser categorizadas nos seguintes termos: a) a discricionariedade, que significa a autonomia que o agente público detém para atuar; b) o monopólio estatal da provisão dos serviços de saúde, ou seja, o Estado como único provedor do serviço de saúde faz com que as pessoas dependam de seus profissionais, logo, em determinadas situações devem pagar as propinas exigidas; c) a falta de accountability, ou seja, a baixa prestação de contas que os agentes públicos devem ofertar à sociedade, ou seja, a resposta que se dá sobre sua atuação em nome do Estado não é devidamente exigida ou provida; d) a falta de transparência: ausência de informação confiável ou da disponibilidade de informação relevante acerca da atuação dos provedores de saúde que interessam à população; e) a falta de voz da sociedade civil: deficiência de mecanismos que permitam as pessoas de expressarem suas necessidades, desejos e concordância ou discordância com as políticas públicas, decisões e resultados em saúde; f) a falta de enforcement: é deficiente aplicação, controle e monitoração da própria força normativa da legislação (Vian, 2008).

No que tange à pressão ou incentivo, sob a perspectiva econômica, a corrupção é incentivada quando o agente é beneficiado com ganhos e sua punição é praticamente improvável. Quanto à pressão, se há uma ambiência que condena moralmente a corrupção, o agente poderá coibir seu ímpeto com receio de ser julgado pelos seus pares.

Quanto à racionalização, as pessoas elaboram para si e outrem razões que justificam suas práticas corruptas. Por exemplo, na Costa Rica, médicos justificam seu absenteísmo com base nos baixos salários (Vian, 2008).

\section{A abordagem de enfrentamento da corrupção baseada nos Direito Humanos}

De acordo com a perspectiva dos direitos humanos, os titulares de direitos e os agentes públicos desempenham papel central na luta contra a corrupção, nesse sentido as estratégias e discussões que envolvem seu enfrentamento devem integrar os princípios internacionais dos direitos humanos, como não discriminação e igualdade, participação, accountability, transparência e devido processo legal , também denominados como "princípios anticorrupção". Singularmente, o princípio da accountability e da transparência são chave para a abordagem baseada nos direitos humanos de enfrentamento da corrupção (OHCHR, 2013). 
Sob o prisma dos direitos humanos, a corrupção erode a confiança nas instituições democráticas e diminui o volume de recursos que devem ser gastos pelos Estados para realizar os direitos humanos, notadamente os direitos sociais e econômicos (Human Rights Council, 2015). Ademais, a corrupção pode ser categorizada como corrupção praticada por agentes públicos, corrupção no setor público, e a executada por agentes não estatais, corrupção no setor privado. Quanto a tal ponto, importa salientar que agentes não estatais desempenham papel crucial na proliferação da corrupção em vários países, conseguintemente, empresas se engajam em atos de corrupção por meio da oferta de propinas a agente estatais ou por meio do recebimento de benefícios ilícitos (OHCHR, 2013).

A interface entre direitos humanos e corrupção pode se conformar de duas formas: violações de direitos humanos resultam de atos de corrupção; e medidas anticorrupção podem infringir direitos humanos. Considerando o foco deste artigo, será dada ênfase ao primeiro modo de configuração da interface. Desse modo, a corrupção pode afetar diretamente indivíduos, como, por exemplo, aqueles que não podem pagar propina para ter acesso a leitos ou medicamentos são discriminados em função de sua renda; por outro lado, sob a ótica de grupos de indivíduos, aqueles que são historicamente marginalizados ou excluídos, como populações indígenas, sofrem de forma mais gravosa o impacto negativo da corrupção quanto à fruição de seus direitos humanos. Sob o ponto de vista das sociedades, a corrupção desloca os recursos públicos destinados aos gastos sociais e os redireciona para fins privados. Com efeito, a corrupção reduz a quantidade de recursos públicos endereçados à provisão dos direitos sociais, como o direito à saúde.

A corrupção e seu enfrentamento implica a conjugação de medidas de natureza preventiva e punitiva. As medidas punitivas que envolvem a responsabilização criminal dos corruptos, a despeito de reconhecer sua relevância, são ineficientes para lidar com a perspectiva da vítima e também de analisar as questões estruturantes que criam oportunidade ou incentivam a prática da corrupção. Sendo assim, o enfrentamento da corrupção com base nos direitos humanos situa a vítima no centro, priorizando as dimensões sociais e econômicas da corrupção. Por exemplo, o Brasil tem a 11ª taxa de homicídio do mundo, segundo a Organização Mundial da Saúde, ou seja, a questão da segurança pública é um problema grave e estruturante de direitos humanos (Agência Estado, 2016). Ocorre que a apropriação de recursos públicos para fins privados repercute na falta de dinheiro para a segurança pública e, consequentemente, na taxa evidentemente elevada de homicídio do país. Portanto, há uma explícita correlação entre a corrupção e a ocorrência de contextos violadores de direitos humanos.

Sob a ótica dos direitos humanos, as medidas preventivas são as mais efetivas para conter a corrupção e evitar seu impacto negativo sobre a fruição de tais direitos. 
Medidas preventivas se consubstanciam em formas de compartilhamento de informação; educação e treinamento e incremento da consciência pública acerca do tema. Ainda, a divulgação de boas práticas e diretrizes pode ser elemento-chave das estratégias de prevenção da corrupção (OHCHR, 2013).

\section{O contexto do SUS e a aplicação da abordagem baseada nos direitos humanos para enfrentamento da corrupção}

Com efeito, considerando o amplo leque de atos de corrupção e suas consequências negativas sobre os variados direitos humanos, enfoca-se tão somente o direito à saúde e, conseguintemente, o SUS, sistema que engloba órgãos e entidades com a finalidade de prover tal direito de forma universal. Com o objetivo de ilustrar modalidades de corrupção que se verificam no âmbito do SUS, e os modos de preveni-las, serão utilizados dois casos apontados pelo Tribunal de Contas da União (FiscSaúde, 2015), o primeiro referente ao Cartão Nacional de Saúde - Cartão SUS - e o segundo ao Programa de Atenção Básica do Ministério da Saúde.

Segundo o citado relatório do Tribunal de Contas da União, o Cartão SUS se encontra previsto nos normativos do Ministério da Saúde desde a segunda metade da década de 90 ,e tem sido anunciado como uma ferramenta fundamental para possibilitar o controle da execução descentralizada dos serviços, diante do caráter nacional e único do sistema público de saúde. Os objetivos são identificar a base de usuários do SUS, acessar o histórico clínico do paciente e melhorar a gestão e a qualidade do atendimento. Porém, ainda segundo o relatório do Tribunal de Contas da União, após gastos vultosos de recursos públicos não se logrou êxito ainda. Em 2004, - Ministério da Saúde determinou que os procedimentos ambulatoriais e hospitalares que exigissem autorização prévia fossem obrigatoriamente acompanhados da identificação dos pacientes por meio do número do Cartão SUS. Com isso, as instituições de saúde públicas e conveniadas passaram a efetuar o cadastramento dos pacientes que não pudessem informar o número do Cartão no ato do atendimento, adotando-se uma numeração provisória que resultou na proliferação de cadastros duplicados (estimados em 27\% dos registros, em 2011). Nos anos seguintes ao término do projeto piloto, não houve evolução significativa na implantação do Cartão SUS, apesar do grande volume de gastos efetuados. Vários problemas foram relatados ao longo dos anos como causas de insucesso na implantação do Cartão SuS, tais como sistemas independentes de cadastramento de pacientes utilizados por vários Municípios, sem integração com o cadastro nacional; expansão não planejada; emissão centralizada do cartão pelo Ministério da Saúde e dificuldades de entrega do cartão definitivo ao seu proprietário; problemas na transmissão dos cadastros para a 
base de dados federal; dentre outros. Sendo assim, no caso do cartão SUS, observase uma combinação de aspectos analisados neste trabalho que envolve especificidades dos sistemas de saúde e fatores que propiciam a corrupção, tais como: gastos vultosos por parte do governo, excesso de discricionariedade dos gestores do SUS, falta de transparência e de accountability.

- segundo caso diz respeito ao Programa de Atenção Básica, que se se caracteriza por um conjunto de ações de saúde, no âmbito individual e coletivo, que abrange a promoção e a proteção da saúde, a prevenção de agravos, o diagnóstico, o tratamento, a reabilitação, a redução de danos e a manutenção da saúde com o objetivo de desenvolver uma atenção integral que impacte na situação de saúde e autonomia das pessoas e nos determinantes e condicionantes de saúde das coletividades. Na prática, não funciona de forma efetiva e enfrenta diversos desafios que foram apresentados no Relatório do Tribunal de Contas da União, do qual pode se extrair que a sua ineficiência se correlaciona com a nomeação de cargos de gestão de saúde de forma política sem considerações de ordem técnica e de meritocracia. A falta de capacitação de profissionais nomeados para sua gestão ocasionou deficiências no Programa que poderiam ser mais bem administradas por recursos humanos adequados. Outro fator que ocasiona sua baixa resolutividade diz respeito à abstenção de profissionais no trabalho. As duas modalidades de corrupção apontadas se interconectam com a presença de pressão e incentivo para a nomeação política de cargos de gestão de saúde, bem como pela racionalização dos profissionais de saúde que justificam seu absenteísmo, mesmo quando tal atitude acarreta implicações graves para a saúde da população (Albuquerque, 2016).

Sob a perspectiva da abordagem baseada nos direitos humanos, enfocam-se dos princípios anticorrupção citados, transparência e accountability. No que tange à transparência, essa envolve os modos governamentais de tomada de decisão, isto é, a sua clareza e visibilidade para toda a população (Toebes, 2011), bem como a divulgação de informação sobre os órgãos e entidades públicas e privadas do setor saúde que são relevantes para sua avaliação pela sociedade civil (Lindstedt, Naurin, 2006). A accountability significa que o agente responsável pelas políticas e programas de saúde tem a obrigação de responder e "dar satisfação" para a sociedade sobre suas ações e deliberações. Considerando o comando derivado da accountability, sob a ótica dos direitos humanos, esse impele à criação de mecanismos para monitorar e acompanhar todos os atores do setor saúde (Toebes, 2011). Considerado os casos acima, constata-se a presença de déficit de transparência e accountability no âmbito do SUS. À luz do exemplo do Cartão do SUS, constata-se que desde a década de noventa as normativas do Ministério da Saúde já o preveem, e gastos com tal objeto são realizados a partir do ano de 2001, ou seja, até o ano de 2015, data da fiscalização do Tribunal de Contas (FiscSaúde,2015), a operacionalização do Cartão ainda 
apresentava diversos problemas. Sendo assim, o Ministério da Saúde não disponibilizou para a sociedade os gastos e decisões que envolveram o Cartão SUS. Nesse sentido, o Portal "Saúde com Mais Transparência", do Ministério da Saúde conta apenas com informações sobre transferências para Estados e Municípios, não há nada sobre o processo de tomada de decisão e as deliberações concernentes às políticas públicas, bem como o Portal se limita a informações sobre o repasse de recursos federais e os efetuados mediante convênios, o que efetivamente não revela se, de fato, os gastos públicos com as ações de saúde foram efetuados. Ainda, destaca-se que embora o Portal informe que se podem acessar planos e relatórios de gestão, esses não constam do Portal.

Quanto à accountability, os mecanismos que buscam assegurá-la na esfera do Poder Executivo, particularmente no caso dos sistemas de saúde, devem assegurar que a execução de políticas e programas de saúde seja de acordo com o propósito da coletividade e não para fins de ganhos privados. A accountability nos sistemas de saúde é determinante para o desempenho dos governos em termos de direitos humanos. Com efeito, a efetiva provisão de serviços de saúde para a população implica que os agentes sejam profissionais e atuem em conformidade com parâmetros de eficiência, técnica e evidências científicas (OHCHR, 2015). Na esfera do SUS, os resultados da autoria do Tribunal de Contas (FiscSaúde, 2015) quanto ao Programa de Atenção Básica apontaram para uma série de falhas de planejamento, capacitação de profissionais, falta de equipamentos e insumos, não cumprimento da carga horária semanal de trabalho, dentre outras. Assim, verifica-se que essas falhas dizem respeito à questão de recursos humanos, quer seja relacionados à gestão ou aos cuidados em saúde. Como a accountability envolve a tomada de postura profissional e comprometida com os resultados para a população, nota-se, a partir do caso de exemplo, que há muito que se aprimorar nesse sentido.

\section{Considerações Finais}

Os sistemas de saúde apresentam peculiaridades que acentuam a ocorrência da corrupção, revelando-se espaços vulneráveis para a atuação de agentes que pretendem usar recursos e bens públicos para ganhos privados. Sob a perspectiva da abordagem em direitos humanos para o enfrentamento da corrupção, como no presente artigo é destacado, há que se enfocar na prevenção por meio da efetivação de medidas anticorrupção, transparência e accountability.

No Brasil, conclui-se que os mecanismos de transparência e accountability, no âmbito do SUS, devem ser aprimorados, consolidados e fortalecidos de modo a se enfrentar veementemente a corrupção na saúde. Constata-se também que a percepção da sociedade brasileira de que recursos da saúde são apropriados por 
agentes privados contribui para minar os movimentos em prol do necessário incremento dos recursos públicos para o financiamento da saúde.

Com efeito, é fato que o aumento do volume de valores para a saúde deve ser acompanhado do real comprometimento com o combate à corrupção, sob pena de crescentes investimentos sem a devida efetividade do sistema para seus usuários.

\section{Referências}

1. ABRASCO. 'O SUS está sendo estraçalhado' entrevista de Gastão Wagner para a Tribuna do Norte. Disponível em: https://www.abrasco.org.br/site/eventos/congresso-brasileiro-de-politicaplanejamento-e-gestao-em-saude/o-sus-esta-sendo-estracalhado-entrevista-degastao-wagner-para-tribuna-norte/28510/. Acesso em: 25 maio 2017.

2. Agência Estado. Brasil tem $11^{a}$ maior taxa de homicídios do mundo, diz OMS. Disponível em: http://www.em.com.br/app/noticia/nacional/2016/05/19/interna_nacional,764128/bra sil-tem-11-maior-taxa-de-homicidios-do-mundo-diz-oms.shtml. Acesso em: 29 maio 2017.

3. Albuquerque A. Direitos Humanos dos Pacientes. Curitiba: Juruá, 2016.

4. Biderman C, Avelino G. A doença da Corrupção: o desvio de Fundos e a Saúde Pública nos Municípios Brasileiros. Biblioteca digital FGV - 2013.

5. Correio Braziliense. Operação investiga fraude em folha de ponto médicos do Hospital de Base. Disponível em: http://www.correiobraziliense.com.br/app/noticia/cidades/2017/03/15/interna_cidade sdf,580798/operacao-investiga-fraude-em-pagamentos-a-servidores-dasaude.shtml. Acesso em: 25 maio 2017.

6. Estadão. Agenda da Anvisa mostra lobby de parlamentares em favor de indústrias. Disponível em: http://saude.estadao.com.br/noticias/geral,agenda-da-anvisamostra-lobby-de-parlamentares-em-favor-de-industrias,875955. Acesso em: 25 maio 2017.

7. Folha de São Paulo. Após máfia das próteses, indústria quer expor pagamentos a médico. Disponível em: http://www1.folha.uol.com.br/cotidiano/2017/05/1885724apos-mafia-das-protestes-industria-quer-expor-pagamentos-a-medicos.shtml. Acesso em: 25 maio 2017.

8. Human Rights Council. Final report of the Human Rights Council Advisory Committee on the issue of the negative impact of corruption on the enjoyment of human rights. 5 January 2015.

9. Jus Brasil. Ministério Público denuncia fraude contra o SUS em Bauru, SP. Disponível em: https://g1-globocom.jusbrasil.com.br/noticias/100202598/ministeriopublico-denuncia-fraude-contra-o-sus-em-bauru-sp. Acesso em: 25 maio 2017.

10. Jus Brasil. Tribunal decreta prisão temporária do prefeito de São Francisco de Itabapoana, por fraude contra o SUS. Disponível em: 
https://abdir.jusbrasil.com.br/noticias/3071687/tribunal-decreta-prisao-temporariado-prefeito-de-sao-francisco-de-itabapoana-por-fraude-contra-o-sus. Acesso em: 25 maio 2017.

11. Lindstedt C, Naurin D. Transparency and Corruption. Disponível em: http://infoa.wdfiles.com/local--files/resursi/Catharina\%20Lindstedt.\%20Daniel\%20Naurin \%202003\%20Transparency\%20Against\%20Corruption\%20_Accepted \%20version_.pdf. Acesso em: 29 maio 2017.

12. Mackey TK et al. The disease of corruption: views on how to fight corruption to advance 21th century global health goals. BMC Medicine (2016) 14:149.

13. Ministério da Saúde. Pesquisa Nacional de Saúde. Disponível em: http://portalsaude.saude.gov.br/index.php/cidadao/principal/agencia-saude/1796171-dos-brasileiros-tem-os-servicos-publicos-de-saude-como-referencia. Acesso em: 25 maio 2017.

14. Portal G1. Médica do Samu é detida com seis dedos de silicone, em Ferraz. Disponível em : http://g1.globo.com/sp/mogi-das-cruzessuzano/noticia/2013/03/medica-do-samu-e-detida-com-seis-dedos-de-siliconeem-ferraz.html. Acesso em: 25 maio 2017

15. R7. Médico troca atestado por voto em Arujá; veja vídeo. Disponível em: http://noticias.r7.com/eleicoes-2016/sao-paulo/medico-troca-atestado-por-votoem-aruja-veja-video-13122016/preview. Acesso em: 25 maio 2017.

16. Savedoff W, Glassman A., Madan J. Global Health, Aid and Corruption: Can We Escape the Scandal Cycle? CGD Policy Paper 086. Washington DC: Center for Global Development;2016. http://www.cgdev.org/publication/global-health-aid-andcorruption-can-we-escape-scandal-cycle.

17. Toebes B. Human Rights, Health Sector and Corruption. Disponível em: http://www.du.edu/korbel/hrhw/workingpapers/2011/64-toebes-2011.pdf. Acesso em: 29 maio 2017.

18. 18. Tribunal de Contas da União. TCU conclui nova versão do FiscSaúde. Disponível em: $\quad$ http://portal.tcu.gov.br/imprensa/noticias/tcu-conclui-nova-versao-dofiscsaude.htm.

19. United Nations Human Rights Office of the High Commisioner. Human Rights and anti-corruption. Disponível em: http://www.ohchr.org/EN/Issues/Development/GoodGovernance/Pages/AntiCorruptio n.aspx. Acesso em: 29 maio 2017.

20. United Nations Human Rights Office of the High Commisioner. The human rights case against corruption. Disponível em: http://www.ohchr.org/Documents/Issues/Development/GoodGovernance/Corruption/ HRCaseAgainstCorruption.pdf. Acesso em: 30 maio 2017.

21. United Nations Human Rights Office of the High Commisioner. Who will be accountable? Human Rights and the Post-2015 Development Agenda. Disponível em: http://www.ohchr.org/Documents/Publications/WhoWillBeAccountable.pdf. Acesso em: 29 maio 2017.

22. Vian T. Corruption in the Health Sector. Disponível em: http://www.bu.edu/actforhealth/CorruptionInHealthforce/Reader\%201.pdf. 
23. Wagner G. Estratégias para consolidação do SUS e do direito à saúde. Disponível: https://www.abrasco.org.br/site/noticias/sistemas-de-saude/estrategias-paraconsolidacao-do-sus-e-do-direito-a-saude-por-gastao-wagner/27784/. Acesso em: 25 maio 2017.

Recebido em: 01/07/2017. Aprovado em: 25/10/2017. 